\title{
Rapid transformation of work integrated learning from the farm to virtual reality
}

\author{
Stuart Barber \\ University of Melbourne \\ srbarber@unimelb.edu.au \\ Rebekah Brown \\ rebekah.brown@unimelb.edu.au
}

Keywords: Work integrated learning, virtual reality, agriculture, veterinary science, experiential learning, farm, extramural.

\section{Abstract:}

All veterinary schools in Australasia require students in the first half of their course to complete work integrated learning (WIL) during vacation time on a range of animal enterprises. This allows students to gain an understanding of how the enterprises function on a day to day basis and compare to the theoretical training that students receive on-campus. The time on-property required is equivalent to 60 days of work with a requirement to visit several enterprises (AVBC, 2016). COVID-19 required immediate cessation of all on-property placements. Given the limited number of holiday weeks available for WIL we developed an on-line experiential program to support student learning.

The backbone of the online WIL experience relied on previously developed or developing virtual reality (VR) farm resources; the 4DVirtual Farm and DookieVR (Barber etal, 2016). These resources allow students to visit properties via multiple 360 images through time on a property, allowing virtual travel through time and place to see what happens on an enterprise throughout a year. They also integrate environmental variables and both 360 and standard video to provide access to further information. They are viewable using mobile phones, laptop and desktop systems as well as VR viewers. The basic VR resource allows students to take their own tour around the property however the week of experiential learning was planned to reinforce the students' ability to see what happens on the individual property throughout the year. This compares to an individual property visit where a student gains more "hands-on" insight for a much more limited timespan of the year, usually 1-2 weeks.

The week of synchronous, experiential learning used Zoom as the primary tool to allow communication between staff and students with content managed on the learning management system, Canvas. The standard format for each day involved an initial entire class group session, mostly in didactic information transfer from staff to students and then a mixture of small group, full class or individual tasks. Assessment of content understanding was evaluated on a regular basis using multiple choice questions or word responses using PollEverywhere. The large class group of 100-250 students broke into small virtual rooms of 6 to 8 students. Each day this small student group had a task to complete and submit via Feedback Fruits, which then allocated individual students to provide written feedback on the group report by the next day. Time was allocated for students to review these reports both individually and then to discuss the multiple reports that group members were assessing and submit feedback. In addition, each small group reported on a relevant name to the veterinary industry, either from current or historical times. A short video detailing the link of this name to the veterinary industry was posted to Flipgrid for both staff and other students to review. Student understanding of the week was measured at the commencement and completion of the week using an online multiple choice quiz as well as receiving student feedback by an online survey. This presentation will cover the background, development and design of the week and associated material.

\section{References}

AVBC (2016), Standard 9.3 Extra Mural Studies (EMS or Workplace Learning), page 32, Australasian Veterinary Boards Council, https://avbc.asn.au/wpcontent/uploads/documents/public/AVBCStandardsAug2016.pdf 
Barber S, Hallein E, Shallcross D, Weston J, Jacobson C, Bramley E, Celi P, McGowan M (2016), Final report: Development of 4D farms to improve student learning and safety, Office of Learning and Teaching https://tr.edu.au/resources/ID12 2365 Barber Report 2016.pdf 